\title{
Effects of Calcium Salts on the Cranberry Fruit Rot Disease Complex
}

\author{
A. B. Blodgett, R. W. Caldwell, and P. S. McManus, Department of Plant Pathology, University of Wisconsin, \\ Madison 53706
}

\begin{abstract}
Blodgett, A. B., Caldwell, R. W., and McManus P. S. 2002. Effects of calcium salts on the cranberry fruit rot disease complex. Plant Dis. 86:747-752.

Calcium salts were applied during the growing season to fresh-fruit cranberry beds to test their effects on cranberry fruit rot incidence and the incidence of specific fungi isolated from rotten and sound cranberry fruit at the time of harvest and after storage. Calcium salts did not affect fruit rot incidence, nor did they affect the recovery of specific fungi from berries. The field treatments did not result in higher calcium content in mature berries, nor did they affect the force required to penetrate the berry epidermis. Calcium propionate inhibited growth in vitro of Allantophomopsis cytisporea, A. lycopodina, Coleophoma empetri, Fusicoccum putrefaciens, and Physalospora vaccinii. Calcium chloride and calcium nitrate inhibited growth of Coleophoma empetri and Fusicoccum putrefaciens, but these salts enhanced growth of Physalospora vaccinii. P. vaccinii was the fungus most frequently isolated from rotten berries at the time of harvest. The fungi most frequently isolated from rotten berries after several weeks in storage varied among sites. $P$. vaccinii, which was common in sound fruit at harvest, persisted in sound fruit in storage but was also isolated frequently from rotten berries after storage. A. lycopodina and $F$. putrefaciens, which were isolated infrequently from sound berries at the time of harvest, were isolated frequently from rotten berries after storage. In two of four trials, no fungi were isolated from a large proportion of fruit that decayed in storage.
\end{abstract}

Additional keywords: Colletotrichum, Godronia, storage rot, Vaccinium macrocarpon, Zygophiala jamaicensis

Fruit rot of cranberry (Vaccinium macrocarpon Ait.) is a disease complex caused by at least 15 different species of fungi $(4,21)$. In practice, fruit rot is classified as either field rot or storage rot, depending on whether disease develops in the field before harvest or in storage after harvest. Although certain fungi are more often associated with rot in the field or in storage, many species are active in both environments. Most fungal infections that result in fruit rot are believed to occur in the field during late bloom and early fruit set, and then after a period of latency, symptoms develop as fruit ripen or while fruit are stored (21). Some fungi, most notably Allantophomopsis spp., which cause black rot in storage, apparently infect fruit through wounds made by harvest machinery (22).

Storage rot is economically important wherever cranberries are produced for the fresh market. In Wisconsin, fresh-market fruit typically receives two to four applications of broad-spectrum protectant fungicides during the growing season. However, the relatively poor disease control, phyto-

Corresponding author: P. S. McManus

E-mail: psm@plantpath.wisc.edu

Accepted for publication 25 February 2002.

Publication no. D-2002-0422-04R

(C) 2002 The American Phytopathological Society toxicity, and human and environmental health risks associated with the use of fungicides (20) have spurred interest in alternative means of managing storage rot. Application of calcium salts has been shown to prolong storage life and improve various measures of quality in several fruit and vegetable crops $(9,10,24)$. Calcium ions bind to pectin in plant cell walls (12), thereby protecting them from degradation by pectolytic enzymes (7-10). Wounding and bruising cranberry fruit predisposes it to fungal storage rot and decay in the apparent absence of microbes, a phenomenon known as "sterile breakdown" $(11,16,22$, 25,26). Therefore, we hypothesized that applying calcium to young, developing fruit would promote ripe berries' resistance to wounding and lead to longer storage life. Moreover, if the calcium salts were directly fungicidal, as has been documented in other systems (1-3), then applying them to developing cranberry fruit would be optimal, as berries are highly susceptible to infection at this stage (21). In fact, this is the developmental stage at which conventional fungicides are believed to be most effective against many fungi in the fruit rot disease complex $(20,21)$.

The primary objective of our study was to test the effects of calcium salts in mitigating storage rot. A secondary objective was to further our understanding of the etiology of cranberry storage rot. In the most recent investigation of storage rot in Wisconsin, Jeffers (20) concluded that
Godronia cassandrae (anamorph: Fusicoccum putrefaciens), Penicillium spp., Allantophomopsis spp., and Coleophoma empetri were the fungi isolated most frequently from rotten cranberry fruit after storage for 3 months at $2^{\circ} \mathrm{C}$. His study, however, was conducted on two farms where cranberries were produced for the processing rather than fresh market, and consequently, fungicides had not been used for at least 10 years. The more intensive fungicide use on fresh-fruit farms could influence the outcome of studies aimed at determining the etiology of storage rot. To address our objectives, we conducted experiments on fresh-fruit farms to test the effects of calcium salts applied during the growing season on: (i) cranberry fruit rot incidence at the time of harvest and after storage; and (ii) the incidence of specific fungi isolated from rotten and sound cranberry fruit at the time of harvest and after storage. In the laboratory, we tested the effects of calcium salts on: (i) growth inhibition in vitro of certain fruit rot fungi; and (ii) the force required to penetrate the berry epidermis.

\section{MATERIALS AND METHODS}

Field trials: experimental design and treatments. Trials were conducted in 1999 and 2000 at commercial cranberry marshes in the major cranberry-growing region of central Wisconsin. At all sites, fruit were grown for the fresh market, and sites had received two to four applications of broadspectrum protectant fungicides per year for several years leading up to the study. During our study, growers omitted fungicides, except at site 3 in 2000, where the grower inadvertently applied copper hydroxide (Champ Formula 2, Agtrol Chemical Products, Houston, TX) at a rate of $3,409 \mathrm{~g} / \mathrm{ha}$ on 29 July. In $1999,1.5 \times 1.5 \mathrm{~m}$ replicate plots were established in a bed of the Searles cultivar at one site. Three treatments, which included two calcium-containing fertilizers and an untreated control, were replicated eight times in a randomized complete block design. The fertilizers were Norplex $(6 \%$ calcium in the form of calcium oxide, Nortrace Ltd., Greeley, CO) and Nutri-Cal ( $8 \%$ calcium in the form of calcium nitrate, CSI Chemical Corp., Bondurant, IA). Fertilizers were mixed with water so that the concentration of calcium was $400 \mathrm{ppm}$ and $600 \mathrm{ppm}$ from calcium oxide and calcium nitrate, respectively. Treatments were applied in the equivalent of 234 liters of water per hectare with a $\mathrm{CO}_{2}$-pressurized hand-held boom sprayer 
on 12 July, 26 July, 10 August, and 24 August, coinciding with late bloom and fruit development. Plots were harvested on 5 October by hand raking, and samples of approximately 500 berries from each replicate plot were transported to the laboratory for further studies.

In $2000,1.0 \times 1.0 \mathrm{~m}$ replicate plots were established in beds of the Stevens, Pilgrim, and Searles cultivars at sites 1, 2, and 3, respectively. Six treatments, which included two laboratory-grade calcium salts, one calcium fertilizer, two conventional fungicides, and an untreated control, were replicated six times in a randomized complete block design. The calcium treatments were calcium nitrate (Sigma Chemical Co., St. Louis, MO), calcium propionate (Acros Organics, Fisher Science Co. LLC, Houston, TX), and Traco Pit-Cal (12\% calcium derived from calcium chloride, Traylor Chemical and Supply Co. Inc., Orlando, FL). Calcium salts were adjusted so that the concentration of calcium was $500 \mathrm{ppm}$. The fungicides and amounts of active ingredient per hectare were Champ Formula 2 (3,409 $\mathrm{g}$ of copper hydroxide) and Bravo WeatherStik $(4,630 \mathrm{~g}$ of chlorothalonil, Syngenta Crop Protection, Inc., Greensboro, NC). All treatments were applied in the equivalent of 468 liters of water per hectare with hand-held garden sprayers on 26 June, 6 July, and 17 July, coinciding with late bloom and early fruit development. Calcium salts were also applied on 28 July, but fungicides were omitted to comply with preharvest restrictions for fresh fruit destined for export. Plots were harvested on 5 October by hand raking, and berries were placed into mesh onion bags and soaked overnight in the water of recently harvested cranberry beds.

Fruit rot incidence. In 1999, disease ratings and fungal isolations were performed at harvest and after 6 and 17 weeks in storage in paper bags at $6^{\circ} \mathrm{C}$ in a laboratory refrigerator. In 2000, disease ratings and fungal isolations were performed at harvest and after 7.5 weeks in storage in mesh onion bags at $5^{\circ} \mathrm{C}$ in an industrial cooler at the Ocean Spray Cranberries receiving station in Babcock, WI. Fruit were sorted into three classes: sound, marketable berries; soft, rotten berries; and berries that were unmarketable for reasons other than fruit rot (e.g., insect damage). For each replicate plot, field rot incidence was calculated for a sample of approximately 200 berries.

Effects of calcium salts on fungal growth in vitro. The effects of three calcium salts on the growth of five fungal species that were previously reported as storage rot pathogens in Wisconsin $(15,20,22,25,27-29)$ were tested in vitro. The fungi were: Allantophomopsis cytisporea, Allantophomopsis lycopodina, Coleophoma empetri, Fusicoccum putrefaciens, and Physalospora vaccinii. Spore suspensions (approximately $6 \times 10^{4}$ spores per $\mathrm{ml}$ of water) were prepared from colonies that had grown from single spores, and the suspensions were spread evenly onto potato dextrose agar (PDA, Becton Dickinson Microbiology Systems, Sparks, MD) to allow a lawn of mycelia to form.

Fungal growth in vitro was tested on yeast nitrogen agar (YNA), which contained $1.7 \mathrm{~g}$ of yeast nitrogen base (Becton Dickinson), $30 \mathrm{~g}$ of dextrose, $3 \mathrm{~g}$ of sodium nitrate, and $15 \mathrm{~g}$ of agar per liter. After autoclaving, the YNA was amended with laboratory-grade calcium salts (calcium chloride, calcium nitrate, or calcium propionate) to reach calcium concentrations of $0,300,600$, and 1,000 ppm. In trials 1 and 3, salt solutions were adjusted to the $\mathrm{pH}$ of the YNA (approximately $\mathrm{pH}$ 5.3); no $\mathrm{pH}$ adjustments were made in trial 2. Equal amounts $(24.5 \mathrm{ml})$ of media were pipetted into $85-\mathrm{mm}$ petri dishes marked with two perpendicular axes in the center. Plates were inoculated by centering a circular plug (4 mm diameter) of mycelia from the fungal lawns on the perpendicular axes. Each treatment was replicated four times for each fungus. Plates were incubated in the dark at $25^{\circ} \mathrm{C}$. Four radial measurements of fungal colonies were taken after $0,5,10$, and 15 days and were averaged to estimate colony area $\left(\pi r^{2}\right)$ at each time point. The radius of the mycelial plug was not subtracted from measurements. The entire experiment was performed three times (referred to as trials 1, 2 , and 3 ).

Force to penetrate epidermis. The force required to penetrate the berry epidermis was measured with a penetrometer (MTS Synergie 2000, Instron, Canton, MA) fitted with a 1.6-mm-diameter probe. For each site in 2000, samples of fruit from the six replicates of each treatment were hand-picked on 22 September, pooled into two replicate samples per treatment, and then separated into three categories based on color intensity (light, blush, and dark). Fruit were sorted by color to eliminate potential variability due to berry maturity. For each of the two replicate samples per treatment, 20 berries in each color category of similar weight and volume were supported on a $15-\mathrm{mm}$ steel ring and compressed at the equator at a rate of $1 \mathrm{~mm} / \mathrm{s}$ to measure the force required to penetrate the epidermis. The experiment was performed separately for berries from each of the three sites in 2000.

Calcium content of fruit. Calciumtreated and untreated control fruit from the penetrometer experiments were analyzed for calcium content by digestion in perchloric and nitric acids followed by inductively coupled plasma optical emission spectrometry at the University of Wisconsin Plant and Soil Analysis Laboratory, Madison.

Fungal isolation and identification. Fungi were isolated from all rotten berries and six arbitrarily chosen sound berries from each treatment replicate at the time of harvest and after 6 and 17 weeks in storage in 1999 and at the time of harvest and after 7.5 weeks in storage in 2000 . However, in 2000 after 7.5 weeks in storage, rather than isolating from all rotten berries, 10 rotten berries per replicate were arbitrarily selected because of the high incidence of storage rot. Berries were surfacedisinfested by brief immersion in $95 \%$ ethanol followed by $5 \mathrm{~min}$ in $0.5 \%$ sodium hypochlorite. Berries were rinsed in three changes of sterile, distilled water, allowed to dry on sterilized paper towels, and then cut in half longitudinally. For each berry, one half was placed with its cut surface down onto PDA amended with streptomycin sulfate $\left(100 \mu \mathrm{ml}^{-1}\right)$ to inhibit bacteria. Each $90-\mathrm{mm}$ petri plate contained two or three berry halves. Black, shiny, pinpoint specks that were clustered near the calyx end of several sound berries were removed from surface-disinfested berries with a sterile needle and placed directly onto PDA. Plates were incubated at $25^{\circ} \mathrm{C}$ with a 12-h photoperiod provided by fluorescent lights. Fungi were identified based on colony appearance and morphological features of spores and spore-producing bodies. Plates were examined at least once per week until all fungi on a plate had been identified. Slower-growing fungi and fungi that could not be readily identified were transferred to new plates. Fungi that did not sporulate but had a fleshy mycelium and produced aerial pegs were tentatively classified as basidiomycetes. Mucoid colonies were tentatively categorized as yeasts and bacteria but were not further identified. Data were recorded as the percentage of berries that yielded various taxa.

Statistical analyses. All statistical analyses were performed using SAS statistical software (Version 8, SAS Institute, Cary, NC). For rot incidence data in 1999, analysis of variance (ANOVA) was performed using the General Linear Model (GLM) procedure with repeated measures to account for correlation due to fruit from the harvest samples being resampled after 6 and 17 weeks in storage. Time variables were highly correlated (0.77 to 0.90$)$, which verified that the repeated measures analysis was appropriate. In 2000, independent samples were taken at harvest and after 7.5 weeks in storage. Therefore, repeated measures analysis was not needed. Rather, ANOVA was performed at each time interval using the GLM procedure, and means were separated using Fisher's protected least significant difference (LSD) test. For the fungal growth rate trials, colony area data were analyzed using the GLM procedure with repeated measures to account for correlation due to measurements of the same fungal colony over time, and treatment means were separated using the LSMEANS procedure. Data from the berry epidermis penetration trials were analyzed using the split-plot model with 
calcium treatment as the whole plot and color category the subplot. Since that analysis showed no significant differences among treatments, data for each site were combined over treatments and analyzed for differences among color categories. Fungal isolation data were analyzed using the GLM procedure, and means were separated using Fisher's protected LSD test.

\section{RESULTS}

Fruit rot incidence. In 1999, fruit rot incidence ranged from 1 to $3 \%$ at the time of harvest; from 4 to $6 \%$ after 6 weeks in storage; and from 4 to $6 \%$ after 17 weeks in storage (data not shown). Differences among the calcium treatments were not significant at any of the time points. In 2000, fruit rot incidence at harvest did not differ significantly among calcium and fungicide treatments at site 1 (Table 1). However at site 2, fruit rot incidence at harvest was significantly greater for the calcium chloride treatment compared with the control, and at site 3, fruit rot incidence at harvest was significantly lower for the chlorothalonil and copper hydroxide treatments compared with the control (Table 1).
After 7.5 weeks in storage, differences in fruit rot incidence among treatments were not significant for any of the sites.

Effect of calcium salts on fungal growth in vitro. Results from the three trials were similar; thus, data are presented only for trial 1 (Table 2). Calcium propionate significantly reduced colony area of all five fungi; colony areas decreased as the calcium propionate concentration in the media increased. Calcium chloride and calcium nitrate significantly reduced colony area of Coleophoma empetri and Fusicoccum putrefaciens, especially after 15 days. Calcium chloride and calcium nitrate significantly increased colony area of Physalospora vaccinii after 10 and 15 days. Colony areas of Allantophomopsis spp. were generally not reduced by calcium chloride or calcium nitrate, and after 10 and 15 days, they were not always reduced by calcium propionate. However, higher concentrations of calcium propionate caused Allantophomopsis lycopodina and Physalospora vaccinii to produce more aerial hyphae, and approximately $25 \%$ of A. lycopodina colonies growing on the highest concentration of calcium propion- ate produced sparse, threadlike hyphae which supported many pycnidia. As the concentration of calcium propionate increased in the media, secretion of a pink pigment by A. cytisporea increased. All three calcium salts caused $C$. empetri to grow irregularly with deeply lobed colony margins.

Force to penetrate epidermis. There was no significant difference among treatments in any color category in the force required to penetrate the epidermis of berries from any of the three sites $(P=$ $0.8084,0.9626$, and 0.9253 for sites 1,2 , and 3 , respectively). However, differences among the color categories were significant $(P<0.0001)$ for each of the three sites, with light fruit requiring 4.4 to $5.1 \mathrm{~N}$ and dark fruit requiring 5.0 to $5.6 \mathrm{~N}$ to penetrate the epidermis.

Calcium content of fruit. Field applications of calcium salts did not have a significant effect on the amount of elemental calcium in fruit 2 weeks prior to harvest (data not shown). Calcium content for all treatments including controls was 0.05 to $0.06 \%$.

Fungal isolation: general remarks. Calcium and fungicide treatments had no

Table 1. Effects of calcium salts and fungicides on cranberry fruit rot incidence (\%) in $2000^{\mathrm{w}}$

\begin{tabular}{|c|c|c|c|c|c|c|c|}
\hline \multirow[b]{3}{*}{ Treatment } & \multirow{3}{*}{$\begin{array}{c}\text { Concentration } \\
(\mathrm{ppm}) \text { or rate } \\
(\mathrm{g} / \mathrm{ha})^{\mathrm{x}}\end{array}$} & \multicolumn{6}{|c|}{ Weeks after storage at $5^{\circ} \mathrm{C}$} \\
\hline & & \multicolumn{3}{|c|}{$\mathbf{0}$} & \multicolumn{3}{|c|}{7.5} \\
\hline & & Site 1 & Site 2 & Site 3 & Site 1 & Site 2 & Site 3 \\
\hline Calcium nitrate & 500 & 4.9 & $4.5 \mathrm{bc}^{y}$ & $5.3 \mathrm{ab}$ & 44.6 & 39.8 & 15.9 \\
\hline Calcium chloride & 500 & 3.9 & $6.8 \mathrm{a}$ & $6.6 \mathrm{ab}$ & 47.7 & 31.2 & 17.0 \\
\hline Calcium propionate & 500 & 6.7 & $5.8 \mathrm{ab}$ & $6.2 \mathrm{ab}$ & 49.5 & 39.2 & 15.0 \\
\hline Chlorothalonil & 4,630 & 5.7 & $3.4 \mathrm{c}$ & $2.2 \mathrm{c}$ & 52.7 & 31.0 & 18.1 \\
\hline Copper hydroxide & 3,409 & 7.0 & $4.4 \mathrm{bc}$ & $4.6 \mathrm{~b}$ & 44.8 & 29.8 & 20.3 \\
\hline Untreated control & $\ldots$ & 4.7 & $4.5 \mathrm{bc}$ & $6.8 \mathrm{a}$ & 52.0 & 27.6 & 16.3 \\
\hline$P^{\mathrm{z}}$ & & 0.7217 & 0.0308 & 0.0021 & 0.7818 & 0.1481 & 0.8726 \\
\hline
\end{tabular}

${ }^{\mathrm{w}}$ Treatments were applied to six replicate plots in a randomized complete block design at each of three sites.

${ }^{\mathrm{x}}$ For calcium salts, the concentration of calcium; for fungicides, the rate of active ingredient.

y Values within a column followed by the same letter are not significantly different according to Fisher's protected least significant difference test.

${ }^{z}$ Significance of $F$ statistics for treatments from analysis of variance.

Table 2. Effect of calcium salts on colony area $\left(\mathrm{mm}^{2}\right)$ of cranberry fruit rot fungi $\mathrm{i}^{\mathrm{y}}$

\begin{tabular}{|c|c|c|c|c|c|c|c|c|c|c|c|}
\hline \multirow[b]{2}{*}{ Fungal species } & \multirow{2}{*}{$\begin{array}{l}\text { Colony age } \\
\text { (days) }\end{array}$} & \multirow{2}{*}{$\begin{array}{l}\text { Unamended } \\
\text { control }\end{array}$} & \multicolumn{3}{|c|}{ Calcium chloride (ppm Ca) } & \multicolumn{3}{|c|}{ Calcium nitrate (ppm Ca) } & \multicolumn{3}{|c|}{ Calcium propionate (ppm Ca) } \\
\hline & & & 300 & 600 & 1,000 & 300 & 600 & 1,000 & 300 & 600 & 1,000 \\
\hline \multirow{3}{*}{$\begin{array}{l}\text { Allantophomopsis } \\
\text { cytisporea }\end{array}$} & 5 & 4,365 & 2,711 & 3,158 & 3,673 & 4,325 & 3,002 & 4,490 & $2,048^{z}$ & 706 & 105 \\
\hline & 10 & 5,542 & 5,542 & 5,542 & 5,542 & 5,542 & 5,542 & 5,542 & 5,542 & 4,605 & 1,484 \\
\hline & 15 & 5,542 & 5,542 & 5,542 & 5,542 & 5,542 & 5,542 & 5,542 & 5,542 & 5,542 & 4,997 \\
\hline \multirow{3}{*}{$\begin{array}{l}\text { Allantophomopsis } \\
\text { lycopodina }\end{array}$} & 5 & 5,000 & 5,253 & 5,182 & 4,581 & 4,276 & 5,230 & 4,928 & 857 & 250 & 29 \\
\hline & 10 & 5,542 & 5,542 & 5,542 & 5,542 & 5,542 & 5,542 & 5,542 & 5,305 & 2,271 & 386 \\
\hline & 15 & 5,542 & 5,542 & 5,542 & 5,542 & 5,542 & 5,542 & 5,542 & 5,542 & 5,238 & 816 \\
\hline Coleophoта & 5 & 902 & 850 & 809 & 861 & 860 & 811 & 781 & 100 & 13 & 13 \\
\hline \multirow[t]{2}{*}{ empetri } & 10 & 3,339 & 2,905 & 2,924 & 2,999 & 3,138 & 2,984 & 2,736 & 463 & 26 & 13 \\
\hline & 15 & 5,298 & 4,209 & 4,278 & 4,009 & 4,594 & 3,915 & 3,402 & 745 & 89 & 13 \\
\hline \multirow{3}{*}{$\begin{array}{l}\text { Fusicoccum } \\
\text { putrefaciens }\end{array}$} & 5 & 108 & 98 & 69 & 99 & 107 & 100 & 115 & 65 & 27 & 13 \\
\hline & 10 & 697 & 600 & 377 & 412 & 602 & 600 & 596 & 349 & 57 & 13 \\
\hline & 15 & 1,464 & 1,204 & 850 & 900 & 1,300 & 1,359 & 1,335 & 816 & 120 & 13 \\
\hline \multirow{3}{*}{$\begin{array}{l}\text { Physalospora } \\
\text { vaccinii (dark) }\end{array}$} & 5 & 480 & 600 & 564 & 560 & 581 & 667 & 587 & 66 & 13 & 13 \\
\hline & 10 & 1,738 & 1,827 & $2,509^{z}$ & 2,256 & 2,249 & 2,621 & 2,170 & 301 & 13 & 13 \\
\hline & 15 & 2,835 & 3,863 & 4,367 & 3,885 & 4,025 & 4,131 & 3,600 & 684 & 21 & 13 \\
\hline
\end{tabular}

${ }^{y}$ Plugs of mycelia of fungi were placed onto yeast nutrient agar that was amended with calcium salts or not amended (control). Colony area was estimated after 5, 10, and 15 days for four replicate plates of each fungus at each calcium concentration. Minimum colony area is $13 \mathrm{~mm}^{2}\left(\mathrm{area}_{\mathrm{r}}\right.$ of the mycelial plug); maximum colony area is $5,542 \mathrm{~mm}^{2}$ (area of the plate).

${ }^{z}$ Values in bold regular font are significantly less than the control for the same time point; values in bold italic font are significantly greater than the control for the same time point. 
consistent effects on the taxa isolated from rotten or sound fruit. Therefore, treatment means for each taxon were averaged, and the grand means are reported for each storage period and site (Table 3 ). Taxa reported include known fruit rot pathogens $(4 ; A$. cytisporea and A. lycopodina, C. empetri, Colletotrichum spp. [presumed anamorphs of Glomerella cingulata], F. putrefaciens, Phomopsis vaccinii, Phyllosticta elongata [anamorph of Botryosphaeria vaccinii], and Physalospora vaccinii) and other taxa if the grand means were greater than $5 \%$ for any storage period $\times$ site. The incidence of berries that yielded no microbes is indicated by the category "none" in Table 3 . Although data for light and dark strains of Physalospora vaccinii are listed separately, the data are combined in the results and discussion presented below. Organisms other than those listed in Table 3 that were isolated from cranberry fruit during the course of this research included Aspergillus spp., Aureobasidium sp., Botrytis sp., Chaetomium sp., Curvularia sp., Fusarium spp., Nigrospora sp., Penicillium spp., Pestalotia sp., Phytophthora spp., Pythium spp., Rhizopus sp., Sclerotinia sp., Septoria spp., Trichoderma spp., and unidentified basidiomycetes, zygomycetes, and yeasts. Zygophiala jamaicensis grew from black, shiny, pinpoint specks removed from sound berries. Less than $5 \%$ of berries yielded fungi that we were unable to classify.

Fungal isolation: rotten fruit. In 1999, the most frequently isolated fungus from rotten fruit at harvest was Physalospora vaccinii; Alternaria spp., Phyllosticta elongata, and Fusicoccum putrefaciens were also isolated frequently (Table 3 ). After 6 weeks in storage, the most frequently isolated fungi were Physalospora vaccinii and Phyllosticta elongata. After 17 weeks in storage, Fusicoccum putrefaciens was by far the most frequently isolated fungus. In 2000, the most frequently isolated taxa from rotten fruit at harvest and after 7.5 weeks in storage varied among sites (Table 3). The major taxa isolated at harvest, in order of prevalence were: at site 1, Physalospora vaccinii, Alternaria spp., bacteria/yeast, and Phomopsis vaccinii; at site 2, Colletotrichum spp. and Phomopsis vaccinii; and at site 3, Physalospora vaccinii, Phomopsis vaccinii, Alternaria spp., and Phyllosticta elongata. The major taxa isolated after 7.5 weeks in storage, in order of prevalence, were: at site 1, Physalospora vaccinii and Phomopsis vaccinii; at site 2, Colletotrichum spp., Physalospora vaccinii, Fusicoccum putrefaciens, and Allantophomopsis lycopodina; and at site 3, A. lycopodina and Physalospora vaccinii. There was a high incidence of berries that yielded no microbes after 7.5 weeks in storage, especially for sites 1 and 2 .

Fungal isolation: sound fruit. In 1999, the most frequently isolated taxa from sound fruit at harvest, in order of prevalence, were Phyllosticta elongata, Alternaria spp., and Physalospora vaccinii (Table 3). These fungi remained prevalent in sound fruit after 6 and 17 weeks in storage. In 2000, the most frequently isolated taxa from sound fruit at harvest and after 7.5 weeks in storage varied among sites, although for any given site, the same fungi were prevalent at harvest and after storage (Table 3). The most frequently isolated fungi at harvest in order of prevalence were: at site 1, Physalospora vaccinii, Alternaria spp., and Phyllosticta elongata; at site 2, Phyllosticta elongata, Colletotrichum spp., Alternaria spp., and Physalospora vaccinii; and at site 3 , Phyllosticta elongata, Alternaria spp., and Physalospora vaccinii. The most frequently isolated fungi after 7.5 weeks in storage in order of prevalence were: at site 1 , Phyllosticta elongata, Alternaria spp., and Physalospora vaccinii; at site 2, Phyllosticta elongata, Colletotrichum spp., Alternaria spp., and Physalospora vaccinii; and at site 3, Phyllosticta elongata and Alternaria spp.

Table 3. Percentage of cranberry fruit yielding various taxa ${ }^{y}$

\begin{tabular}{|c|c|c|c|c|c|c|c|c|c|}
\hline \multirow[b]{4}{*}{ Taxon } & \multicolumn{9}{|c|}{ Weeks in cold storage ${ }^{z}$} \\
\hline & & & & \multicolumn{6}{|c|}{2000} \\
\hline & \multicolumn{3}{|c|}{1999} & \multicolumn{2}{|c|}{ Site 1} & & & & \\
\hline & $\mathbf{0}$ & 6 & 17 & $\mathbf{0}$ & 7.5 & $\mathbf{0}$ & 7.5 & $\mathbf{0}$ & 7.5 \\
\hline \multicolumn{10}{|l|}{ Rotten fruit } \\
\hline Allantophomopsis cytisporea & 2 & 1 & 1 & 1 & 2 & 1 & 3 & 6 & 10 \\
\hline Allantophomopsis lycopodina & 5 & 6 & 4 & 2 & 9 & 3 & 17 & 6 & 30 \\
\hline Coleophoma empetri & 10 & 1 & 6 & 10 & 3 & 12 & 6 & 4 & 14 \\
\hline Colletotrichum spp. & 3 & 1 & 0 & 8 & 0 & 66 & 21 & 6 & 4 \\
\hline Fusicoccum putrefaciens & 22 & 10 & 71 & 4 & 9 & 6 & 18 & 1 & 8 \\
\hline Phomopsis vaccinii & 0 & 0 & 0 & 15 & 20 & 26 & 4 & 32 & 13 \\
\hline Phyllosticta elongata & 25 & 41 & 19 & 3 & 1 & 7 & 3 & 22 & 3 \\
\hline Physalospora vaccinii (light) & 9 & 8 & 5 & 2 & 1 & 1 & 2 & 4 & 2 \\
\hline Physalospora vaccinii (dark) & 33 & 37 & 21 & 18 & 22 & 9 & 18 & 46 & 16 \\
\hline Alternaria spp. & 30 & 19 & 5 & 19 & 8 & 10 & 4 & 22 & 8 \\
\hline Epicoccum spp. & 8 & 5 & 0 & 2 & 1 & 1 & 0 & 0 & 0 \\
\hline Bacteria/yeast & 10 & 9 & 2 & 17 & 4 & 8 & 7 & 19 & 14 \\
\hline None & 2 & 7 & 7 & 0 & 32 & 0 & 22 & 0 & 12 \\
\hline \multicolumn{10}{|l|}{ Sound Fruit } \\
\hline Allantophomopsis cytisporea & 1 & 1 & 1 & 0 & 0 & 1 & 0 & 1 & 1 \\
\hline Allantophomopsis lycopodina & 0 & 1 & 0 & 2 & 1 & 1 & 1 & 4 & 1 \\
\hline Coleophoma empetri & 0 & 0 & 2 & 2 & 1 & 5 & 3 & 2 & 3 \\
\hline Colletotrichum spp. & 1 & 1 & 1 & 2 & 3 & 48 & 49 & 3 & 3 \\
\hline Fusicoccum putrefaciens & 7 & 3 & 8 & 3 & 7 & 2 & 4 & 1 & 2 \\
\hline Phomopsis vaccinii & 0 & 0 & 0 & 9 & 13 & 4 & 6 & 14 & 15 \\
\hline Phyllosticta elongata & 74 & 92 & 85 & 19 & 35 & 62 & 66 & 78 & 73 \\
\hline Physalospora vaccinii (light) & 3 & 5 & 7 & 3 & 0 & 3 & 1 & 2 & 2 \\
\hline Physalospora vaccinii (dark) & 30 & 26 & 24 & 39 & 22 & 23 & 17 & 20 & 15 \\
\hline Alternaria spp. & 40 & 42 & 35 & 23 & 29 & 39 & 44 & 54 & 56 \\
\hline Epicoccum spp. & 11 & 12 & 7 & 6 & 9 & 6 & 3 & 10 & 5 \\
\hline Cladosporium spp. & 10 & 9 & 5 & 1 & 1 & 1 & 2 & 1 & 1 \\
\hline Nodulisporium sp. & 5 & 4 & 10 & 8 & 5 & 2 & 3 & 0 & 1 \\
\hline Bacteria/yeast & 4 & 4 & 1 & 6 & 0 & 4 & 0 & 2 & 0 \\
\hline None & 0 & 0 & 0 & 0 & 7 & 0 & 0 & 0 & 0 \\
\hline
\end{tabular}

${ }^{y}$ Data are grand means of eight replicates of three treatments (two calcium salts and an untreated control) in 1999; six replicates of six treatments (three calcium salts, two fungicides, and an untreated control) in 2000.

${ }^{\mathrm{z}}$ Fruit were stored at $6^{\circ} \mathrm{C}$ in 1999 and $5^{\circ} \mathrm{C}$ in 2000 . 


\section{DISCUSSION}

The relatively poor efficacy of fungicides in controlling storage rot and phytotoxicity associated with their use (20) prompted our study of the effects of calcium salts on the cranberry fruit rot complex. Unfortunately, calcium salts applied during the growing season did not reduce field or storage rot incidence, nor did they uniformly affect which species of fungi were isolated from rotten or sound berries. These results might be explained by the fact that treated berries apparently did not incorporate calcium, as indicated by tissue analysis of mature berries. Vaccinium spp., such as cranberry, are calcifuges; that is, they have low leaf concentrations of calcium and thrive in acidic soils poor in calcium (19). Thus, it may be that cranberry is inherently unresponsive to supplemental calcium. However, in an unrepeated trial in Washington (23), application of lime (calcium carbonate) at rates of 1,000 to 2,000 $\mathrm{kg} / \mathrm{ha}$ to a cranberry planting in January increased calcium content of fruit by 14 to $21 \%$ and significantly reduced decay of fruit after 3 weeks in storage at $3^{\circ} \mathrm{C}$ compared with the untreated control.

We applied calcium at berry set and during the early stages of berry development, when cell growth and division would be rapid (6). On apple, three or four foliar applications of calcium chloride are recommended during the early stages of fruit development ( 1 to 7 weeks after petal fall), and again 4 and 2 weeks prior to anticipated harvest (30). On cranberry, we applied calcium four times to match the maximum number of fungicide sprays typically applied by fresh fruit growers in Wisconsin, and we used rates within the range recommended on product labels. However, calcium uptake might have been enhanced by additional applications in the field, using higher rates, pressure infiltration, or applying calcium as a postharvest drench, as described for other fruit and vegetable crops $(9,10)$. For example, field applications of calcium chloride to highbush blueberry did not reduce incidence of rotten berries, nor did it increase berry firmness or calcium content (17). However, calcium chloride applied as a postharvest drench did increase the firmness of highbush blueberries (18). It is also possible that uptake of calcium by cranberry fruit might vary depending on maturity. For example, infiltration of calcium was less effective in immature than mature apple fruit (10).

Although none of the calcium salts reduced fruit rot incidence or influenced the recovery of specific fungi from berries, calcium propionate significantly reduced colony area of all fungi screened, and calcium chloride and calcium nitrate reduced colony area of Coleophoma empetri and Fusicoccum putrefaciens, especially after 15 days (Table 2). Previously, calcium propionate was the most effective of sev- eral calcium salts in reducing hyphal growth of Monilinia fructicola (3) and Colletotrichum spp. (1); calcium chloride was also inhibitory in those studies. Interestingly, colony area of Physalospora vaccinii was greater on media amended with calcium nitrate or calcium chloride compared with the control, suggesting that this fungus metabolizes components of the added salts.

Although cranberry fruit destined for fresh market sales is raked or combed rather than beaten from vines, mechanical harvest is traumatic and results in bruising and wounding of berries. Wounds serve as infection courts for Allantophomopsis spp. (22), and bruising predisposes fruit to fungal rot and sterile breakdown $(11,16,22$, $25,26)$. We hypothesized that increasing the calcium content of fruit would increase the resistance of berries to injury during harvest. In fact, calcium treatments did not increase the force required to penetrate the fruit epidermis; however, as noted above, the treatments failed to increase calcium levels in fruit. The greater force required to penetrate the epidermis of darker fruit was expected, because the cuticles of darker berries are thicker and more densely embedded with waxes than cuticles of lighter berries (13).

In determining the etiology of storage rot, it is difficult to distinguish between primary pathogens and fungi that are merely associated with rotten fruit. To address this problem, we identified the fungi associated with sound berries at the time of harvest and then monitored which species persisted in storage in sound berries and which species were isolated from rotten berries after several weeks in storage. Since fruit rot is not contagious in storage (i.e., a rotten berry is not a source of inoculum for nearby berries [14]), we presumed fruit decay in storage to be due to pathogens in or on sound fruit at the time of harvest or sterile breakdown. Physalospora vaccinii, which was common in sound fruit at harvest, persisted in sound fruit in storage but was also isolated frequently from rotten berries after storage (Table 3), suggesting that it is a storage rot pathogen. As expected, Allantophomopsis lycopodina and Fusicoccum putrefaciens, which previously have been reported as important storage rot pathogens $(15,20,22$, 25,27-29), were effective storage rot pathogens in our study; their levels were often low to moderate in sound fruit at harvest but higher in rotten fruit after storage (Table 3). However, in contrast to the most recent study in Wisconsin (20), Penicillium spp. and Coleophoma empetri were not commonly isolated from fruit that rotted in storage.

At the time of harvest, sound berries always yielded at least one fungal colony, with Phyllosticta elongata isolated most frequently (Table 3). However, after storage, especially in 2000, a significant pro- portion of rotten berries yielded no fungi. This apparent disappearance of fungi in storage is puzzling. It is probably not due to low temperatures, because fungi persisted in fruit that remained sound after several weeks in storage. Perhaps as sound berries undergo physiological decline in storage, they become poor hosts for Phyllosticta elongata. A decrease in viability of this one species could account for the increased frequency of rotten berries that yielded no fungi after storage.

Fruit were dry-raked in both years, but in 2000, fruit were immersed in harvest floodwater overnight to simulate commercial harvest practices. This step likely accounted for the higher incidence of storage rot in 2000 and influenced the results of fungal isolation. For example, Ceponis and Stretch (5) reported that storage rot incidence was nearly four times greater for water-harvested fruit than for dry, handpicked fruit, and rot incidence was greatest when fruit were immersed in harvest floodwaters for $24 \mathrm{~h}$ before being stored. The greater occurrence of Allantophomopsis spp. in 2000 is consistent with reports of these pathogens being waterborne (22) and black rot incidence being directly proportional to the length of time that fruit are immersed in harvest floodwater (31). Likewise, longer immersion times have led to more sterile breakdown in storage (32), which could explain the much greater incidence of sterile breakdown in 2000 than in 1999 in our study. The nature of sterile breakdown is not well understood, but the possibility that microbes that were not cultured under standard conditions play a role has not been eliminated. Whatever the cause, our study corroborates previous reports that sterile breakdown causes major postharvest losses of cranberry fruit in Wisconsin (20,25,27-29).

Overproduction has driven the price of cranberries sold for processing from a high of $\$ 65$ per barrel $(45.4 \mathrm{~kg})$ in 1997 to less than $\$ 10$ per barrel in 2000. By contrast, fresh fruit and certified organic fruit markets remain lucrative, stimulating interest in storage quality and alternatives to conventional pesticides for storage rot management. Various calcium salts and copperbased fungicides are listed with the Organic Materials Review Institute as permitted in organic production. Unfortunately, calcium salts and copper hydroxide did not reduce the incidence of cranberry fruit rot in our study. However, if methods were developed to ensure the uptake of calcium by developing fruit, then the prospects might be more promising.

\section{ACKNOWLEDGMENTS}

We thank V. Best, T. Dittl, L. Kummer, and A. Vasanthakumar for assistance in the field and laboratory; P. Crump and R. Kethyreddypally for statistical advice; and J. Palta and G. Stanosz for reviewing an earlier version of the manuscript. This research was funded by University of Wisconsin System Applied Research Grants program 
and University-Industry Relations Industrial \& Economic Development Research program.

\section{LITERATURE CITED}

1. Biggs, A. R. 1999. Effects of calcium salts on apple bitter rot caused by two Colletotrichum spp. Plant Dis. 83:1001-1005.

2. Biggs, A. R., El-Kholi, M. M., and ElNeshawy, S. M. 1994. Effect of calcium salts on growth, pectic enzyme activity, and colonization of peach twigs by Leucostoma persoonii. Plant Dis. 78:886-890.

3. Biggs, A. R., El-Kholi, M. M., El-Neshawy, S., and Nickerson, R. 1997. Effects of calcium salts on growth, polygalacturonase activity, and infection of peach fruit by Monilinia fructicola. Plant Dis. 81:399-403.

4. Caruso, F. L., and Ramsdell, D. C. 1995. Compendium of Blueberry and Cranberry Diseases. American Phytopathological Society, St. Paul, MN.

5. Ceponis, M. J., and Stretch, A. W. 1983. Berry color, water-immersion time, rot, and physiological breakdown of cold-stored cranberry fruits. HortScience 18:484-485.

6. Chandler, F. B. 1952. Preliminary report on the development of cranberry fruit. Cranberries-The Nat. Cranberry Mag. 17:6-7.

7. Conway, W. S., Gross, K. C., Boyer, C. D., and Sams, C. E. 1988. Inhibition of Penicillium expansum polygalacturonase activity by increased apple cell wall calcium. Phytopathology 78:1052-1055.

8. Conway, W. S., and Sams, C. E. 1984. Possible mechanisms by which postharvest calcium treatment reduces decay in apples. Phytopathology 74:208-210.

9. Conway, W. S., Sams, C. E., and Kelman, A. 1994. Enhancing the natural resistance of plant tissues to postharvest diseases through calcium applications. HortScience 29:751-
754.

10. Conway, W. S., Sams, C. E., McGuire, R. G., and Kelman, A. 1992. Calcium treatment of apples and potatoes to reduce postharvest decay. Plant Dis. 76:329-334.

11. Davis, D. C., and Shawa, A. Y. Reducing injury during mechanical harvesting of cranberries. J. Am. Soc. Hortic. Sci. 108:444-447.

12. Demarty, M., Morvan, C., and Thellier, M. 1984. Calcium and the cell wall. Plant Cell Environ. 7:441-448.

13. Farag, K. M., and Palta, J. P. 1989. Ultrastructure and surface morphology of cranberry plant (Vaccinium macrocarpon Ait.) with reference to ethrel penetration. Acta Hortic. 241:378-384.

14. Franklin, H. J. 1916. Report of cranberry substation for 1915. Mass. Agric. Exp. Stn. Bull. 168.

15. Friend, R. J. 1968. Incidence and pathogenicity of fungi found on cranberry in Wisconsin. $\mathrm{Ph} . \mathrm{D}$. thesis. University of Wisconsin, Madison.

16. Graham, S. O., Patterson, M. E., and Allen, B. 1967. Bruising as a predisposing factor in the decay of stored cranberries. Phytopathology 57:497-501.

17. Hanson, E. J. 1995. Preharvest calcium sprays do not improve highbush blueberry (Vaccinium corymbosum L.) quality. HortScience 30:977-978.

18. Hanson, E. J., Beggs, J. L., and Beaudry, R. M. 1993. Applying calcium chloride postharvest to improve highbush blueberry firmness. HortScience 28:1033-1034.

19. Hope-Simpson, J. F. 1938. A chalk flora of the Lower Greensand: Its uses in interpreting the calicole habit. J. Ecol. 26:218-235.

20. Jeffers, S. N. 1991. Effects of fungicides applied during bloom on yield, yield components, and storage rots of cranberry. Plant Dis. 75:244-250.
21. Oudemans, P. V., Caruso, F. L., and Stretch, A. W. 1998. Cranberry fruit rot in the Northeast: A complex disease. Plant Dis. 82:11761184.

22. Schwarz, M. R., and Boone, D. M. 1985. Effect of wounding on incidence of black rot of cranberry in Wisconsin. Plant Dis. 69:225227.

23. Shawa, A. Y. 1979. Effect of lime on yield and keeping quality of 'McFarlin' cranberries. HortScience 14:50-51.

24. Shear, C. B. 1975. Calcium-related disorders of fruits and vegetables. HortScience 10:361365.

25. Shear, C. L., Stevens, N. E., and Bain, H. F. 1931. Fungous diseases of the cultivated cranberry. U.S. Dep. Agric. Tech. Bull. 258.

26. Shear, C. L., Stevens, N. E., Wilcox, R. B., and Rudolph, B. A. 1918. Spoilage of cranberries after harvest. U.S. Dep. Agric. Bull. 714.

27. Stevens, N. E., and Bain, H. F. 1927. Storage rots of cranberries in the 1926 crop. Phytopathology 17:649-655.

28. Stevens, N. E., and Bain, H. F. 1928. Storage rots of cranberries in the 1927 crop. Phytopathology 18:809-814.

29. Stevens, N. E., and Bain, H. F. 1929. Storage rots of cranberries in the 1928 crop. Phytopathology 19:1037-1039.

30. Stiles, W. C., and Reid, W. S. 1991. Orchard Nutrition Management. Cornell Cooperative Extension Bull. 219, Ithaca, NY.

31. Stretch, A. W., and Ceponis, M. J. 1983. Influence of water immersion time and storage period on black rot development in coldstored, water-harvested cranberries. Plant Dis. 67:21-23.

32. Stretch, A. W., and Ceponis, M. J. 1986. Fungal and physiological breakdown in six cranberry cultivars following water harvesting and cold storage. HortScience 21:265-267. 